\title{
Perbandingan Kinerja Reservoir Gas Konvensional dengan Coal Bed Methane (CBM)
}

\author{
Suranto \\ Dosen Teknik Perminyakan UPN Veteran Yogyakarta
}

\begin{abstract}
Abstrak
Reservoir gas konvensional yang dikenal oleh masyarakat luas adalah reservoir yang terdiri dari jebakan reservoir (cap rock), batuan reservoir dan isi (gas). Sedangkan perangkapnya bisa berupa perangkap struktur, stratigtafi, patahan atau kombinasi dari ketiganya. Sedangkan reservoir yang menghasilkan gas methane batubara (Coal Bed Methane yang disingkat $\mathrm{CBM}$ ) merupakan zona batubara yang terisolasi, memiliki rekah alam dan terisi oleh air. pada kondisi awal kedua tipe reservoir ini (reservoir gas konvensional dan CBM) mempunyai karakteristik yang berbeda, sehingga teknik perhitungan cadangan, cara memproduksikan dan kinerjanya akan berbeda pula. Karena mempunyai latarbelakang yang berbeda maka kiranya perlu dilihat kinerjanya seberapa jauh perbedaannya karena keduanya memproduksikan gas hidrokarbon.
\end{abstract}

Untuk melihat kinerja reservoirnya baik reservoir gas konvensional atau CBM maka dalam kajian ini menggunakan simulator. Dari kedua model, volume masing-masing reservoir dibuat sama, dan dilakukan sensitivitas karakteristik reservoirnya terhadap masing-masing model. Hasil akhir yang dibandingkan adalah kinerja dari masing-masing reservoir tersebut.

Hasil yang didapat dari kajian ini adalah bahwa reservoir CBM mempunyai laju produksi gas lebih rendah, daerah pengurasan lebih kecil dan recovery factor lebih sedikit bila dibandingkan dengan reservoir gas konvensional. Tetapi karena cadangan gas konvensional semakin lama semakin menipis, maka reservoir CBM sebagai alternatif yang perlu dikembangkan setelah gas konvensional. Kebijakan pajak pemerintah sangat penting untuk kelangsungan produksi CBM.

Kata-kata kunci: Reservoir Gas Konvensional,Coal Bed Methane (CBM)

Corresponding author e-mail address: su_ranto@upnyk.ac.id

\section{PENDAHULUAN}

Dengan berjalannya waktu, energi yang bersumber dari fosil semakin lama semakin menipis, karena jenis energi ini tidak dapat diperbaharui. Oleh sebab itu perlu dilakukan alternatif lain, untuk mendapatkan gas selain dari gas konvensional. Salah satu sumber gas selain dari gas konvensional adalah gas methane batubara (coal bed methane). Secara perolehannya CBM lebih sulit bila dibandingkan dengan gas konvensioal, tetapi perolehan gas selain konvensional yang paling dekat tingkat kesulitannya adalah CBM. Gambar 1 merupakan kenampakan dari tingkat kesulitan eksplorasi gas ditinjau dari keteknikannya (Holditch, 2003). Dari gambar tersebut dapat dilihat bahwa semakin sulit gas untuk dieksploitasi, jumlahnya semakin banyak, , karena manusia cenderung untuk mengambil yang lebih mudah dulu daripada yang susah. 


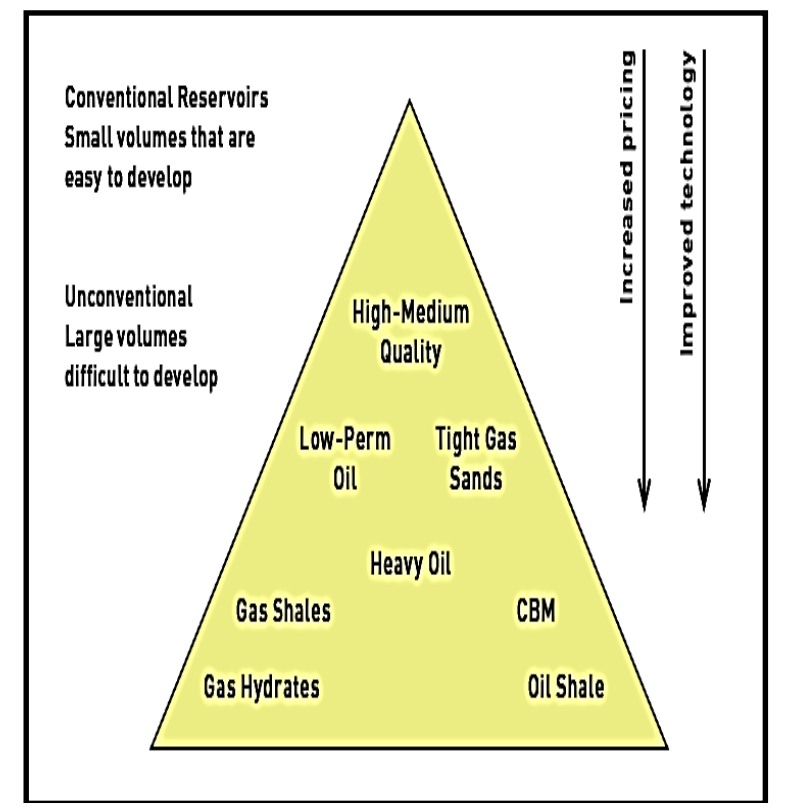

Gambar 1. Resource triangles (Holditch, 2003)

Untuk memberikan gambaran yang lebih jelas tentang kinerja reservoir CBM, maka dibuat model reservoir CBM dan kemudian dibandingkan dengan model reservoir gas konvensional.

\section{METODOLOGI}

Dalam menggambarkan kinerja reservoir konvensional dengan reservoir CBM, menggunakan alat simulator reservoir. Alat ini berupa program computer (software). System kerja software ini adalah mengubah persamaan deferensial parsial yang rumit pada aliran fluida didalam batuan menjadi persamaan yang lebih sederhana dengan metode finite different. Karena metode tersebut memerlukan perhitungan secara berulang-ulang (iterasi) maka pekerjaan perhitungan harus menggunakan computer.

\section{TINJAUAN PUSTAKA}

\subsection{Reservoir CBM}

Reservoir Coalbed Methane terdapat pada zona batubara yang mempunyai porositas. Porositas ini umumnya terbentuk setelah lapisan batubara itu terbentuk yaitu berupa rekahan (fracture). Gas yang terkandung di CBM bukan merupakan gas bebas tetapi dalam bentuk ter-adsorpsi. Gas bebas bisa muncul di pori-pori batuan jika tekanan saturasinya sudah terlampaui. Gambar 2, merupakan sketsa dari reservoir CBM. Dari gambar tersebut terlihat bahwa pada awalnya gas ter-adsorpsi didalam batubara, dan dengan penurunan tekanan, maka gas keluar menuju pori-pori batuan. Oleh sebab itu, didalam perhitungan cadangan secara volumetric ada berbeda dengan perhitungan cadangan gas konvensional. 


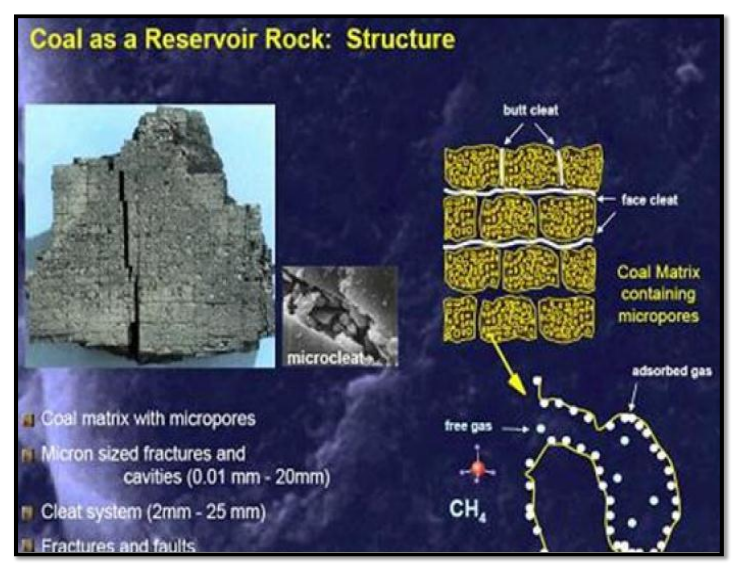

Gambar 2. Sistim dual porosity pada batubara sebagai reservoir (Sitaresmi, Abdassah, Marhaendrajana, \& Irawan, 2008)

\subsection{Perhitungan Cadangan Volumetrik}

Berdasarkan sifat tersimpannya gas yang ter-adsorpsi dibatubara maka perhitungan cadangan secara volumetrik dilakukan sebagaiberikut :

G= 1359.7.A .h .pB. Gc

Dimana :

$\mathrm{G}=$ Gas in Palce, $\mathrm{SCF}$

A $=$ Drainage Area, Acre

$\mathrm{H}=$ Ketebalan, $\mathrm{ft}$

$\mathrm{pB}=$ Average Coal Bulk Density, g/cc

Gc = Average Gas Constant, scf/ton

Sedangkan untuk reservoir gas konvensional cadangan secara volumetric dihitung dengan persamaan :

$$
\mathrm{G}=(43560 . \mathrm{Vb} \cdot \phi \cdot(1-\mathrm{Sw})) / \mathrm{Bg}
$$

Dimana :

$\mathrm{G}=$ Gas in Place, $\mathrm{SCF}$

$\mathrm{Vb}=$ Bulk Volum, Acre-ft

$\boldsymbol{\phi}=$ Porosity, fraksi

$\mathrm{Sw}=$ Water saturation, fraksi

$\mathrm{Bg}=$ Gas volume factor, $\mathrm{cu} \mathrm{ft/scf}$

\subsection{Pemodelan Reservoir}

Dalam memodelkan reservoir baik reservoir gas konvensional maupun reservoir CBM dapat dilihat di Gambar 3. Sesuai dengan karakteristiknya yang disusun dari rekahan-rekanan, maka seolah-olah disusun dari beberapa kubus yang diantara kubus tersebut merupakan rekahannya. Porositas matriks terdapat didalam kubus sedangkan porositas fracture berada di antara kubus. Jika terjadi proses pengurasan reservoir, maka fluida yang keluar terlebih dulu yang berasal dari fracture (antar kubus) dan setelah itu, maka disusul dari porositas yang berasal dari matriks. 


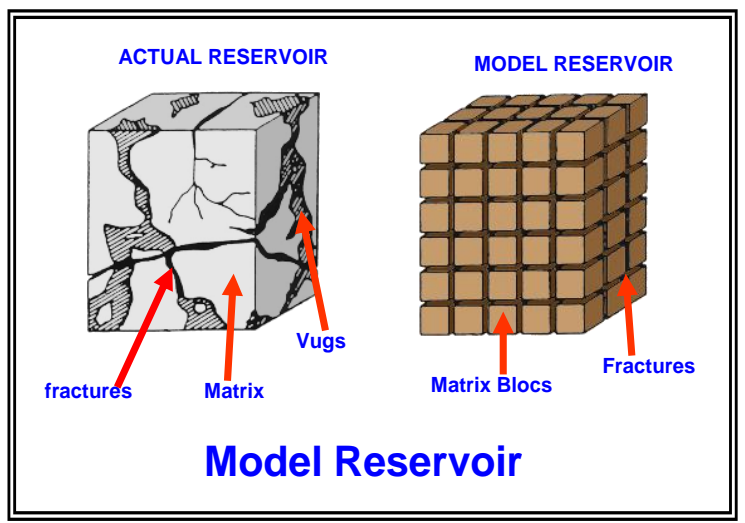

Gambar 3. Modifikasi dari Model Warren dan Root untuk Menggambarkan Reservoir Rekah (Warren \& Root, 1963)

\section{CONTOH KASUS DAN PEMBAHASAN}

Sebagai obyek dari penelitian ini, data yang digunakan adalah lapangan CBM yang ada di Sumatera Selatan. Ketebalan dan struktur diasumsikan seragam dan sifat fisik batuan dan fluida dianggap homogen. Data lain yang tidak tersedia dilakukan asumsi tetapi masih dalam kisaran yang normal. Untuk mendapatkan harga kisaran yang normal dapat dilihat disimulator. Tabel $\mathbf{1}$ adalah data yang digunakan untuk pemodelan reservoir gas konvensional dan CBM yang menjadi obyek kajian.

Setelah data tersebut dimasukkan kedalam simulator, maka menghasilkan model seperti yang terlihat pada Gambar 4. Baik model gas konvensional atau CBM mempunyai bentuk dan ukuran reservoir yang sama dan yang membedakan adalah kondungan didalamnya. Seperti yang terlihat dalam tabel 1, bahawa reservoir gas konvensional pada kondisi inisial sudah terdapat gas bebas, sedangkan CBM baru muncul kalau sudah ada penurunan tekanan hingga tekanan saturasinya.

Tabel 1. Pemodelan Reservoir Gas Konvensional dan CBM

\begin{tabular}{|l|c|c|}
\hline \multicolumn{1}{|c|}{ Uraian } & $\begin{array}{c}\text { Reservoir gas } \\
\text { konvensional }\end{array}$ & Reservoir CBM \\
\hline Jenis Grid & Orthogonal & Orthogonal \\
Jumlah Grid & $36 \times 32 \times 4=4608$ buah & $36 \times 32 \times 4=4608$ buah \\
Grid Aktif & 4608 buah & 4608 buah \\
Ukuran 1 grid & $50 \times 50 \times 10 \mathrm{ft}$ & $50 \times 50 \mathrm{x} \mathrm{10 \textrm {ft }}$ \\
Sistim Porositas & Dual porositas & Dual porositas \\
Jumlah Sektor & 1 buah & 1 buah \\
Batas Gas Minyak (GOC) & $1640 \mathrm{ft}$ & - \\
Tekanan Awal & $600 \mathrm{Psi}$ & 600 Psi \\
Sumur Produksi & 5 Sumur & 5 Sumur \\
Porositas fracture & 0.10 (fraksi) & 0.10 (fraksi) \\
Permeabilitas fracture & $10 \mathrm{mD}$ & $10 \mathrm{mD}$ \\
Porositas matriks & 0.02 & 0.02
\end{tabular}




\begin{tabular}{|l|c|c|} 
Permeabilitas matriks & $2 \mathrm{mD}$ & $2 \mathrm{mD}$ \\
Fracture Spacing & 0.2 & 0.2 \\
Coal desorbtion time (Ch4) day & - & 50 \\
Coal desorbtion time (CO2) day & - & 50 \\
Global Composition (CH4) & - & 0.8 \\
Global Composition (CO2) & - & 0.2 \\
Langmuir Adsorbtion Constant & - & $3 \mathrm{E}-41 / \mathrm{psi}$ \\
(CH4) & - & 0.357 \\
Maximum Adsorbed Mass (CH4) & - & 0.538 \\
gmol/lb & & 0.9 \\
Maximum Adsorbed Mass (CO2) & 0.3 & \\
gmol/lb & & \\
Water Saturation & & \\
\hline
\end{tabular}

\subsection{Inisialisasi Model}

Setelah proses pemasukkan data lengkap kedalam model, maka dilakukan inisialisasi. Proses inisialisasi ini bertujuan untuk mendapatkan reservoir pada kondisi mula-mula sebelum dilakukan gangguan (proses produksi). Yang perlu dilakukan pengecekkan terhadap proses ini adalah: jumlah cadangan, distribusi tekanan dan saturasi fluida. Kondisi ini dicocokkan dengan studi geologi sebelumnya, karena pada saat inisialisasi ini memerlukan data geologi yang bersifat statis. Dari proses inisialisasi ini didapat cadangan seperti yang terdapat pada tabel 2, sedangkan top struktur dari kedua model tersebut dapat dilihat Gambar 4.

Tabel 2. Hasil Inisialisasi dari Model

\begin{tabular}{|c|c|c|}
\hline Parameter & CBM & $\begin{array}{c}\text { Gas } \\
\text { Konvensional }\end{array}$ \\
\hline $\begin{array}{c}\text { Original Gas in } \\
\text { Place (OGIP), } \\
\text { SCF }\end{array}$ & $1.14 \mathrm{E}+09$ & $1.32 \mathrm{E}+09$ \\
\hline $\begin{array}{c}\text { Original Water } \\
\text { in Place (OWIP), } \\
\text { STB }\end{array}$ & $6.00 \mathrm{E}+06$ & $3.34 \mathrm{E}+05$ \\
\hline
\end{tabular}




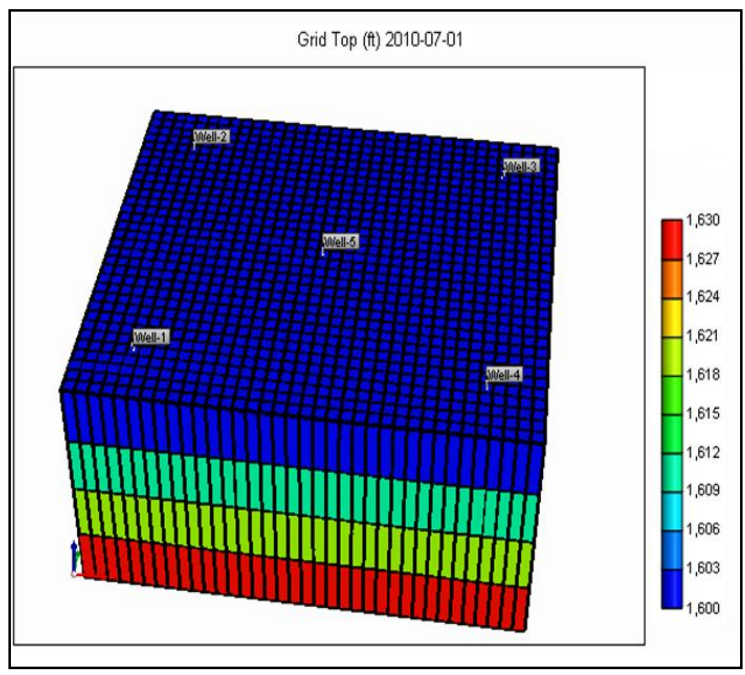

Gambar 4. Top Stuktur dari Model Reservoir Gas Konvensional atau CBM

\subsection{Skenario Model}

Skenario model dilakukan untuk mendapatkan hasil dari sensitivitas model. Ada lima (5) scenario yang buat dalam model dan masing-masing scenario mempunyai perubahan variable seperti yang terdapat pada tabel 3 .

Tabel 3. Perlakuan model terhadap masing-masing scenario

\begin{tabular}{|c|c|c|}
\hline $\begin{array}{c}\text { Skenario } \\
\text { Model }\end{array}$ & $\begin{array}{c}\text { Gas } \\
\text { Konvensional }\end{array}$ & CBM \\
\hline $\begin{array}{c}\text { Base Case } \\
(1)\end{array}$ & $\mathrm{K}=10 \mathrm{mD}$ & $\mathrm{K}=10 \mathrm{mD}$ \\
\hline 2 & $\mathrm{~K}=15 \mathrm{mD}$ & $\mathrm{K}=15 \mathrm{mD}$ \\
\hline 3 & $\mathrm{~K}=5 \mathrm{mD}$ & $\mathrm{K}=5 \mathrm{mD}$ \\
\hline 4 & $\begin{array}{c}1 \text { Sumur } \\
\text { Produksi, } \mathrm{q}=0.3 \\
\text { MMCF/day }\end{array}$ & $\begin{array}{c}1 \text { Sumur } \\
\text { produksi, } \mathrm{q} \\
\text { max }\end{array}$ \\
\hline 5 & $\begin{array}{c}1 \text { Sumur } \\
\text { Produksi, } \mathrm{q}=1.5 \\
\text { MMCF/day }\end{array}$ & \multicolumn{1}{|c}{-} \\
\hline
\end{tabular}

Catatan : Semua skenario menggunakan Tekanan alir dasar sumur $(\mathrm{Pwf})=50 \mathrm{psi}$ 


\subsection{Pembahasan}

Pemodelan ini dimaksudkan untuk membandingkan kinerja reservoir gas konvensional dengan reservoir CBM. Dalam model telah dilakukan sensitivitas seperti yang terlihat dalam skenario pemodelan (tabel 3). Skenario tersebut dimaksudkan untuk mencari variabel yang paling sensitif terhadap kinerja reservoir. Gambar 5 adalah laju produksi dari reservoir gas konvensional dan reservoir CBM. Dari kelima skenario dapat dilihat bahwa karakter dari reservoir gas konvensional sangat berbeda bila dibandingkan reservoir CBM. Laju produksi gas yang berasal dari gas konvensional dapat diatur sesuai dengan kebutuhan yang ada, sehingga laju produksi bisa konstan. Setelah tekanan sudah tidak mampu lagi untuk mencukup laju produksi yang ditentukan, baru mengalami penurunan (decline). Keadaannya akan berbeda jika dibandingkan dengan reservoir CBM. Di awal produksi, laju produksi tidak bisa diatur secara konstan. Di awal produksi akan memproduksikan air terlebih dahulu, sehingga dengan turunnya tekanan maka gas mulai keluar. Hal ini disebabkan karena reservoir CBM tidak mengandung gas bebas seperti reservoir gas konvensional. Gas bebas bisa muncul jika penurunan tekanan reservoirnya sudah melampaui tekanan saturasinya. Walaupun tekanan saturasi sudah terlampaui, tetapi tidak serta merta laju produksi constan, karena keluarnya gas dari batubara bersifat dinamis. Oleh sebab itu maka, reservoir gas CBM tidak bisa berproduksi secara konstan. Gambar 6, adalah produksi kumulatif masing-masing skenario. Reservoir gas konvensional karena mudah diatur laju produksinya maka diakhir masa produksi akan cenderung mempunyai kumulatif produksi yang relatif sama. Pengaturan laju produksi bertujuan untuk mempercepat atau memperlambat pengurasan. Perbedaan laju produksi yang menyolok di skenario 3 dan 5 semata-mata karena factor pengurasan. Setiap sumur akan mempunyai area pengurasan sendirisendiri sehingga keterbatasan pengurasan akan berpengaruh terhadap laju produksi yang dihasilkan.

Persoalan daerah pengurasan akan samadengan di reservoir CBM. Seperti yang terlihat di skenario 4, ternyata meskipun produksi dimaksimalkan hingga $1 \mathrm{MMSCF} / \mathrm{Day}$, tetapi reservoir tidak mampu untuk memenuhinya sehingga hanya dapat berproduksi maksimal 0.05 MMSCF/hari. Hal ini disebabkan oleh daerah pengurasan yang kecil dan keluarnya gas methane dari batubara tidak konstan. Semakin cepat pengurasan reservoir, maka akan berdampak pada semakin cepat juga penurunan tekanan reservoir. Seperti yang terlihat pada Gambar 7, bahwa penurunan tekanan reservoir yang paling cepat adalah pada skenario 2, yaitu permeabilitas masing-masing reservoir $15 \mathrm{mD}$. Dengan naiknya permeabilitas, maka kedua reservoir tersebut akan memproduksikan gas yang lebih banyak dan daerah pengurasan reservoir semakin lebar. Pada skenario ini, baik reservoir gas konvensional atau reservoir gas CBM mempunyai karakteristik yang sama. 

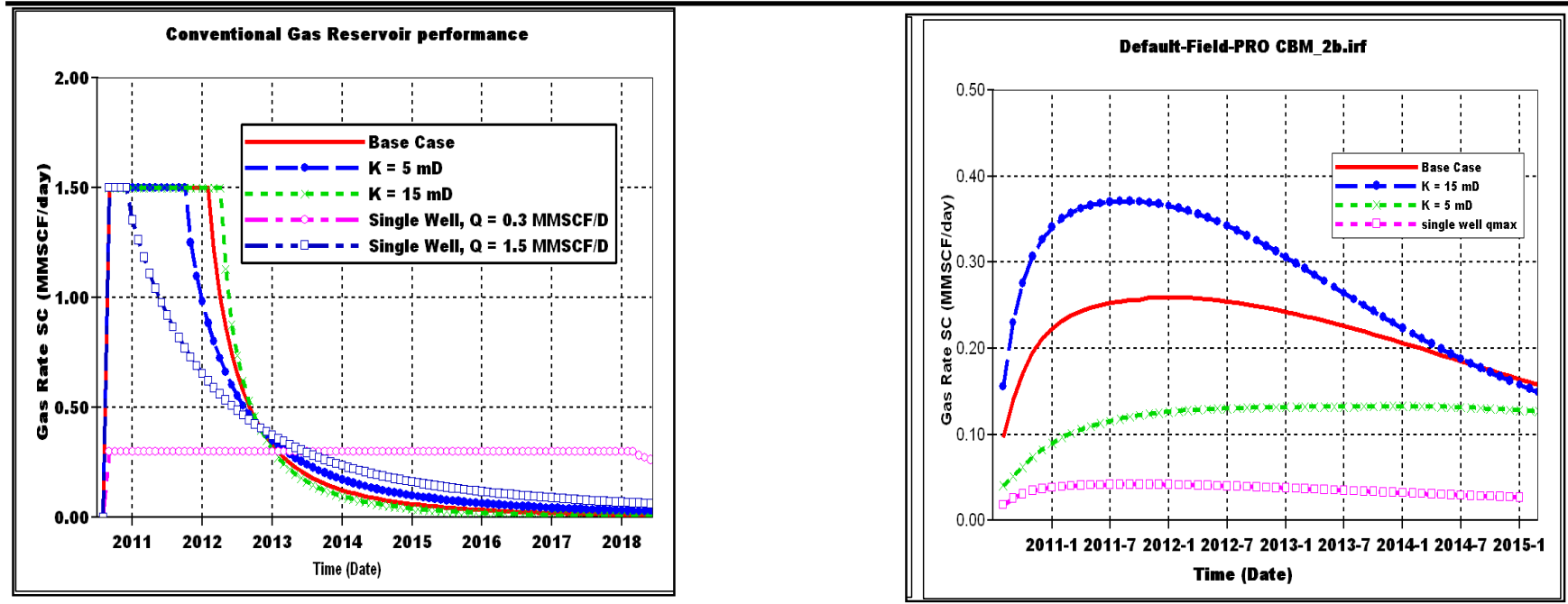

Gambar 5. Perbandingan Laju Produksi gas Skenario Base case, 2,3 dan 4
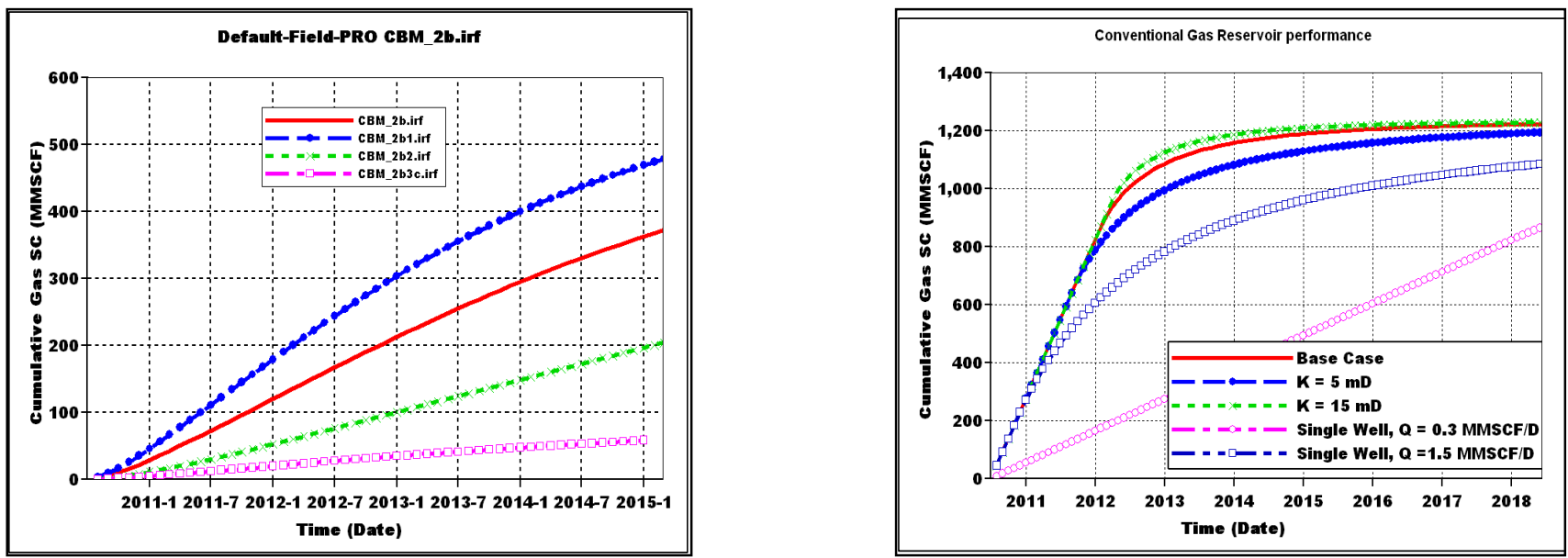

Gambar 6. Perbandingan Produksi Kumulatif Gas Skenario Base case, 2 ,3 dan 4
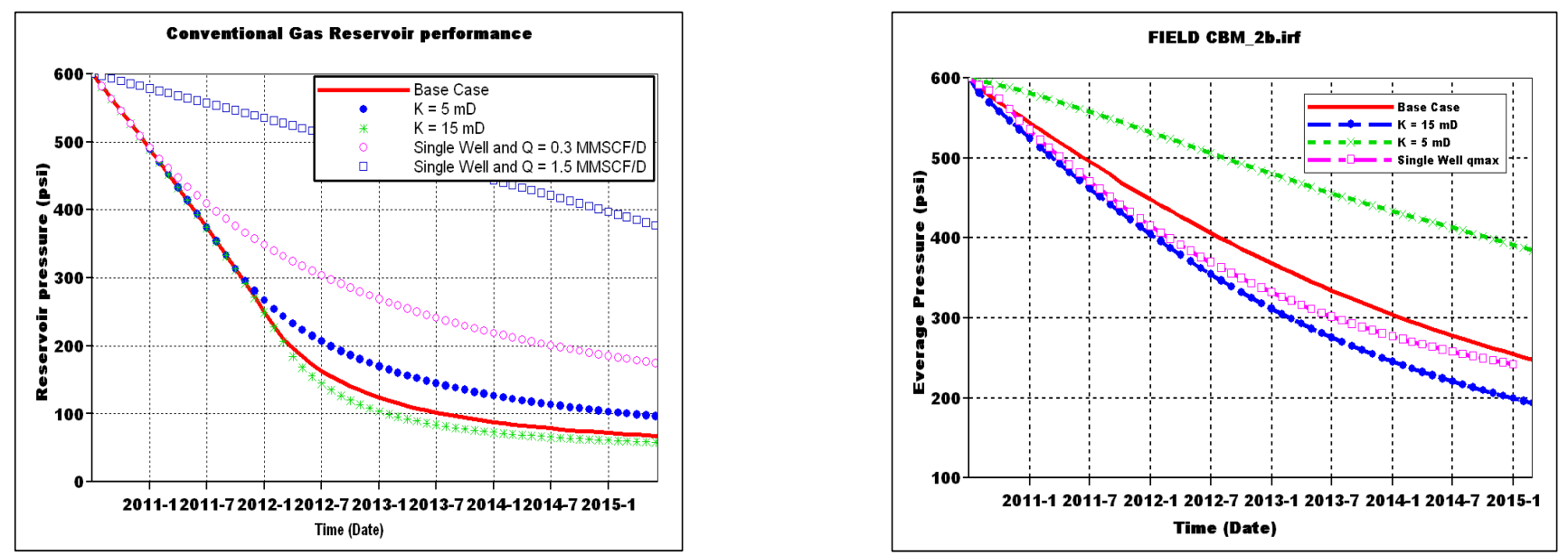

Gambar 7. Perbandingan Tekanan rata-rata Lapangan Skenario Base case, 2,3 dan 4 
Perbandingan recovery factor secara keseluruhan dari masing-masing scenario dapat dilihat di tabel 4. Kalau dilihat dari factor perolehannya, maka reservoir gas konvensional lebih tinggi bila dibandingkan reservoir CBM, hal ini karena reservoir gas konvesional, sudah ada gas bebas yang ada direservoir, sedangkan reservoir CBM baru ada gas bebas kalau penurunan tekanan sudah melampaui tekanan saturasinya.

Tabel 4. Recovery Factor Diawal Tahun 2015

\begin{tabular}{|c|ccc|c|}
\hline Skenario Model & $\begin{array}{c}\text { Kumulatif Produksi gas } \\
\text { Gas Konvensional (MMSCF) }\end{array}$ & $\begin{array}{c}\text { Kumulatifif Porduks gas } \\
\text { CBM (MMSCF) }\end{array}$ & $\begin{array}{c}\text { Recovery Factor } \\
\text { Gas Konvensional }\end{array}$ & $\begin{array}{c}\text { Recovery Factor } \\
\text { CBM (\%) }\end{array}$ \\
\hline Base Case (1) & 1188.95 & 405.35 & 89.74 & 35.48 \\
\hline 2 & 1209.23 & 525.36 & 91.27 & 45.99 \\
\hline 3 & 1128.24 & 195.97 & 85.16 & 17.16 \\
\hline 4 & 493.50 & 72.23 & 37.25 & 6.32 \\
\hline 5 & 959.73 & - & 72.44 &. \\
\hline
\end{tabular}

\section{KESIMPULAN}

Dari uraian diatas, maka dapat disimpulkan sebagai berikut :

1. Dengan nilai permeabilitas yang sama, ternyata laju produksi Gas reservoir CBM lebih rendah dari reservoir gas konvensional.

2. Tingkat pengurasan reservoir lebih jauh reservoir gas konvensional bila dibandingkan dengan reservoir CBM, sehingga reservoir CBM perlu sumur yang lebih banyak.

3. Pengaturan laju produksi di reservoir gas konvensional lebih mudah bila dibandingkan dengan reservoir CBM.

4. Recovery factor yang didapat dalam kurun waktu yang sama, reservoir CBM lebih rendah bila dibandingkan dengan reservoir gas konvensional.

\section{DAFTAR PUSTAKA}

de Haan, H., Godderij, R., van Hulten, F., \& Scheffers, B. (2010). Unconventional Gas in The Netherlands. Lecture Petroleum-Geologische Kring (PGK) of the Koninklijk Nederlands Geologisch Mijnbouwkundig Genootschap. The Hague: Petroleum Geologische Kring.

Holditch, S. A. (2003). The Role of 10Cs nad NOCs in Developing Unconvensional Oil and Gas Reservoir. Texas: Texas A\&M University.

Makino, E., Sosrowidjojo, I. B., \& Suwarno, P. (2006). CBM Development in South Sumatera. Jakarta: IndoCBM. 
Remner, D. J., Ertekin, T., Sung, W., \& King, G. R. (1986). A Parametric Study of the Effects of Coal Seam Properties on Gas Drainage Efficiency. SPE Reservoir Engineering, 633-646.

Sitaresmi, R., Abdassah, D., Marhaendrajana, T., \& Irawan, D. (2008). Metode Peramalan dan Produksi Gas Metana Batubara Menggunakan Korelasi dari Data Produksi Aktual. IATMI Simposium dan Kongres X. Jakarta: IATMI.

Stevens, S. H. (2006). Resource and Development Potential. Jakarta: IndoCBM.

Warren, J. E., \& Root, P. J. (1963). The Behavior of Naturally Fractured Reservoirs. SPE Journal, 245255. 